Ljubomir Drakulevski ${ }^{1}$, Leonid Nakov²

1"Ss. Cyril and Methodius" University in Skopje, Faculty of Economics

2"Ss. Cyril and Methodius" University in Skopje Faculty of Economics

\title{
Managing Business Model as Function of Organizational Dynamism
}

UDC: $005.721 / .722$

DOI: 10.7595/management.fon.2014.0025

XIV International Symposium SymOrg 2014, 06 - 10 June 2014, Zlatibor, Serbia

One of the most challenging managerial attempts nowadays is undoubtedly an attempt to create a business model which will best integrate the organizational position and the external adaptation and integral integration. This managerial process is a logical continuation of modelling a competitive advantage of a certain enterprise, in such a way that the organizational learning would best integrate the used, not the overall organizational knowledge; the flexibility of the organizational systems wwill determine the potential of the behavioural processes and the changes oriented towards innovation will enable strategic positioning regarding the existing and potential competition.

The prior objective of creating and further managing a business model is to achieveg an integrated and proactive combination of elements that implement the needs of an organizational dynamism, in the process of problem analyzing the sustainable dimensions of the competitive advantage. Therefore, the ultimate target is managing a customer-integrated business model, as one that places an 'integrated importance' to the role of the customer within managing the organizational competitive advantage.

Keywords: Organizational inertia and dynamism, pro-activity, strategic positioning and flexibility, customer-integrated business model

\section{Introduction}

Business modelling and the process of managing it has emerged on the basis of importance of applicative usage from the mid 1960's when dynamic companies, such as IBM - generally framing the computer from the industrial to the predominantly personal, Sears Roebuck - in shifting from overall catalogue offer to a retailing specialized catalogues, Motorola - from consumer electronics- operating method to high-technology added value in telecommunications, mobile and Internet based competitive model, IKEA - from immense non compositional to separate segmented business offer, and many others, have identified the necessity of changing the dominant business logic, with regards to the contingency analyses of the internal and external stimuli, determinants and obstacles to a prominent and recognizable sustained competitiveness.

Each organized effort in planning and implementing a certain business model integrates not only the organizational, but also the departmental level, especially to those organizational units which are most critical to a proper determination and combination of business elements whose relationship and inter-dependence forms the scope and depth of the competitive potential of any enterprise. In this context, business modelling is a process rather than a state, predominantly due to the needed changes, transformational or transactional, that shape the process of managing it.

\section{Methodological determination and elements of Business model}

Despite the fact that applicative importance of business modelling has emerged from the mid 1960's, up to the end of 1990's there has not been a unified and accepted methodological framework for managing an organizational business model, which interrelates with the increase in the need for a planned, not an incidental organizational change, mainly focused on changes towards adopting the strategies concerning the complex environment. However, it is quite important to emphasize that the concept of business modeling is 
far from applying the organizational strategy, or operative accommodation of strategic elements. In detailing the desired nature and capacity of their business model, every organization focuses on their particular combination of resources - especially the used knowledge, skills, capabilities and experience, on one hand, with the capacity for proactive behavior, strategic flexibility and organizational inertia, on the other hand, both of which aimed at reaching the state of organizational dynamism.

The fundamental logic of the business model is finding out the key value - adding resources and capabilities and integrating them in accordance with the organizational strategy, structure, systems and human resources. Theoretical defining of a business model presents a variety of methodological approaches, which determine it as follows:

* The method of doing business by which a company can sustain itself through generating revenue (Chesbrough \& Rosenbloom, 2002);

* Firm's intended or actual response to how value is created or appropriated (Magretta, 2002)

\$ Design of organizational structures (Baden-Fuller \& Morgan, 2010), such as boundary - spanning transactive structures (Amit \& Zott, 2001);

\$ An operational tool expressing the business logic of an organization (Osterwalder, 2004);

\& A convention between partners concerning the generation and sharing of value among stakeholders Nerstraete \& Jouison, 2007);

\& A firm's underlying logic and strategic choices to create and capture value within a value network (Shafer, Smith \& Linder, 2005) and the most prominent and influencing definition in the business modelling literature is:

\# An architecture for the product or service, an information flow, a description of the benefits for the business actors involved and a description of the sources of revenue (Timmers, 1998).

It is evident from a majority of the above detailed definitions that the business model initially refers to using a 'dual business developmental perspective', in terms th

at it simultaneously stipulates, in our profound analyses, the following organizational counterparts:

* Pragmatism and innovative changes;

* Integrity and particularization;

* Management and leadership;

* Adaptively and proactively performing

* Short-term profit orientation and long-term business value maximization;

- Strategic choices and user generated operational context etc.

Each business model integrates various constitutional elements, predominantly determined and described through the following Table:

Table 1: Business model elements

\begin{tabular}{|c|c|c|}
\hline No. & Element of business model & Description \\
\hline 1. & Value proposition & An overall view of the company's bundle of products and services \\
\hline 2. & Target customer & Segments of customers a company wants to offer value to \\
\hline 3. & $\begin{array}{l}\text { Customer } \\
\text { handling/distribution channel }\end{array}$ & Various means of the company to get in touch with its customers \\
\hline 4. & $\begin{array}{l}\text { Customer } \\
\text { interfaces/relationship }\end{array}$ & $\begin{array}{l}\text { Kinds of links a company establishes between itself and its different } \\
\text { customer segments }\end{array}$ \\
\hline 5. & Value configuration & Arrangement of activities and resources \\
\hline 6. & Capability/core competency & Competencies necessary to execute the company's business model \\
\hline 7. & Partner network & $\begin{array}{l}\text { Network of cooperative agreements with other companies necessary to } \\
\text { efficiently offer and commercialize value }\end{array}$ \\
\hline 8. & Cost structure & Monetary consequences of the means employed in the business model \\
\hline 9. & Revenue model & A way a company makes money through a variety of revenue flows \\
\hline
\end{tabular}

Source: Adopted according to Osterwalder, A., Pigneur, Y. \& Tuchi, C.L. (2005), Clarifying Business Models: Origins, Present and Future of the Concept, Communication of the AIS, Vol.16 (1), p.13 
1. The initial element of each business model is value proposition, which refers to the perceived value benefit, which a customer would get from the specific combination of the organizational products or services. It precisely determines the quality features from the organizational offer which are prevalent for the customer. This first element details the cognitive offer view which, in fact, is dominant for the perceived value from the transactions with the specified organization.

2. In order to accommodate the numerous products or services to the most particular customer demand, an organization has to undertake changes in order to position itself in front of the target customer the model of interdependence starts from identifying the customer portfolio which can be best served with organizational products and services that have undergone transactional or transformational changes. The importance of this second business model element lies in a clear determination of the customer wishes, tendencies, motives, expectations, benefits etc., received with the act of purchasing the product or the service.

3. The process of achieving a full alignment with the identified needs, in a broader meaning of the word, includes a proper way of handling them, through the distributive channels. As a third element, the customer handling/distribution channel integrates all communicational approaches in order to create a sense of satisfaction in a specific customer, in terms of mutual articulating, gestures, emphasizing common interest of both sides etc. This element is absent only at public tenders, in which case this element is included in the customer interface/relationship.

4. Each customer, as a member of various determined target customer segments, possesses different means of establishing and developing a closer relationship, which is accomplished in the customer interfaces/relationship element. It implies that, with regards to the handling method, the complete relationship is built with an accent on the stimulus for a customer segmented satisfaction, which is highly important especially for the higher customer segments that need a clear distinction in satisfying their determined needs.

5. Immediately after the relations with the customers have been established, the company should create a specific combination for optimal usage of its resources and capabilities, particularly processes and activities which add value for the customers, which is accomplished in the fifth business model element - value configuration. It is important that each organizational configuration of resources and capabilities must be unique in comparison with other companies, as well as in comparison with various customer segments. It details the capacity of the organization to be original in satisfying its customers.

6. In certain circumstances, an organization may be able to integrate its resources and capabilities proactively, but will not bear the required competencies for implementing the desired business model - it is the focal point of the sixth element, i.e. capability/core competency. As an applicative element, it stipulates that core organizational competencies are expected to be sustained, and therefore to influence a more complete delivery of the promised organizational outcome - benefit from the products or services for the customers.

7. Partner network, as an element of the business model, refers to the undeniable truth that no organization can be specialized in every business function. The tendency for finding out a solid and serious network of business partners would result in bringing about a higher quality of performance at lower cost. It focuses upon an increased efficiency and, at the same time, upon commercializing the benefits that arise from the achieved value for the targeted customers.

8. It is useful to measure the invested money in increasing the level of satisfaction of the customer segments. Therefore, in the element named cost structure, an organization makes efforts to leverage the benefits, in order to determine which means of effecting value configuration are a priority, and which are of a second level of importance. The cost structure should not lower the promised quality level to the customers, and at the same time it is not expected to be based on a non-sustainable combination of resources and capabilities.

9. Finally, the business model finalizes with the creation of the revenue model - which implies that an organization should determine the level of risk exposure for different revenue flaws, in order to enable itself to put priority to those that are best suited to the contingency combination of internal and external elements. The importance of the revenue model is in categorizing the revenue flows in accordance with the degree of prosperity and potential for influencing its competitive advantage.

Every element of the business model affects both the fulfillment of the consecutive one and the overall effectiveness and efficiency of the already created business model, in which the most creative and sensitive elements usually are the target customer, the value configuration, the building capability/core competency and the partner network. 
A categorization of the elements of the business model which pays due attention to using transformational strategy for changes is detailed as constituted of the following integral business model elements ${ }^{1}$ :

* Value proposition,

\$ Nature of inputs,

* How to transform inputs (including technology),

* Nature of outputs,

\# Vertical scope,

* Horizontal scope,

\# Geographic scope,

\& Nature of customers,

\$ Organization of the model.

The most important difference of the last model from the first, previously detailed business model, is in the position of the customers, and that is on the 8-th level. The prior reason for it lies in the fact that in strategic modelling of the business, customers are initially positioned, as an element which influences to all other elements. In this context, customers on the 8-th level may manifest certain variability with regards to a closer integration of the resource/capability combination compared to the desired level of customer satisfaction.

In addition to these two business model concepts, the most intriguing issue in creating and managing the most efficient business model is in the proper combination of resources and competencies, aimed at adding value to the organizational performance. A model which pays most attention to it is named the RCOV model (Resources and Competencies, Value Proposition, Organization), in which each combination of the resources and competencies is measured through its marginal influence to the customer quantitative and qualitative benefits. The presentation of the approach, in combining the elements of this configurative business model would best be detailed in the following Figure:

Figure 1: The RCOV Business model (Demil \& Lecocq, 2010)

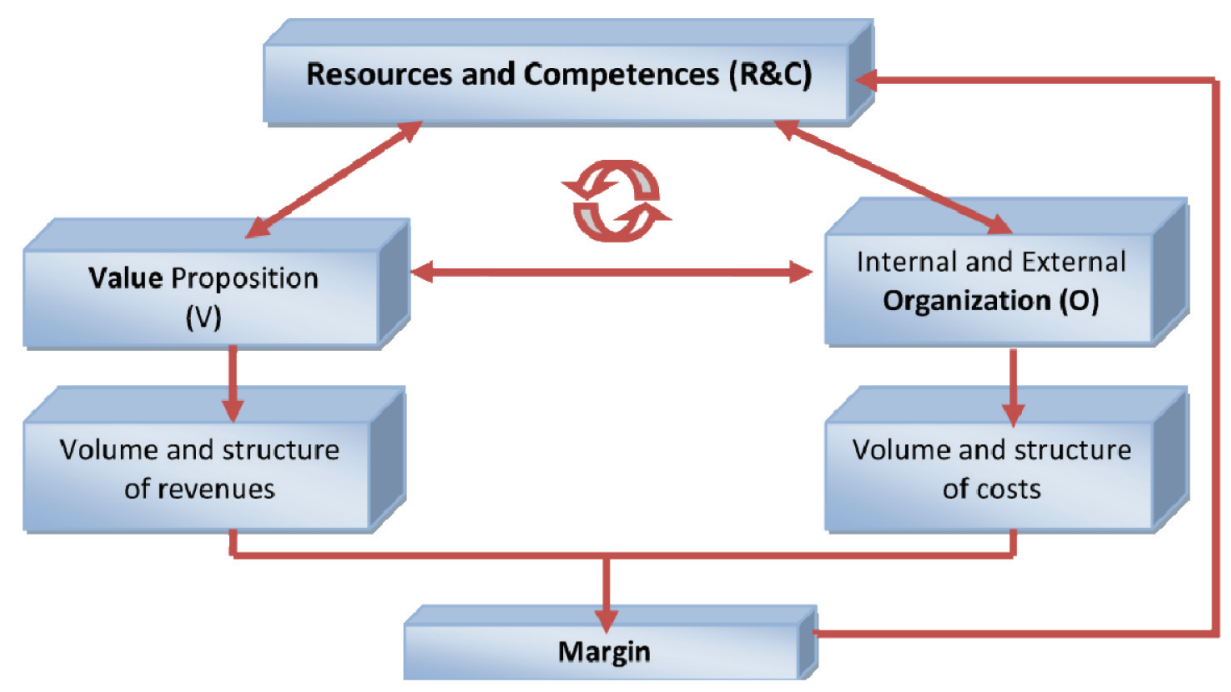

It is evident that the integration of elements of the RCOV business model is done through organizational and customer learning, socialization and acquisition of new customers, offer specification, production and/or distribution by the customers, resulting in the customer-integrated character of this model, although the customer $\mathrm{him} /$ herself is not an element of the model, but may appear within the external organization dimension. 


\section{Managing Proactivity, Organizational inertia, Strategic positioning and flexibility for Organizational dynamism}

In order to increase the level of successfulness, each business model is expected to execute certain management criteria for success of a business model${ }^{2}$, among which, as most applicable, arise the following:

* A proactive business approach that turns thoughts into looking out for business and our marketing strategies to creating a need and away from a current business model where marketing focuses on fulfilling a need and waiting for the customer to ring, undertaken through these managerial steps:

$\checkmark$ Figuring out the company culture,

$\checkmark$ Putting a business plan in place,

$\checkmark$ Showing leadership, and

$\checkmark$ Recruiting and retaining top performers.

* Business model constitutes a change in the company culture, one that allows us to plan and one that still maintains a sense of urgency. The new culture is about creating more opportunities and building relationships.

Organizational proactivity is higher in an experienced organization, in comparison with young and start-up companies, in which the manifestations of organizational inertia, especially the structural one, emerge owing to the managerial determination ${ }^{3}$ that is less subject to structural inertia; young organizations may seem more adaptive than established firms, but their agility depends critically on the availability of resources to pursue multiple paths, aimed at reaching the strategic continuity.

The integration of proactivity and organizational inertia leads to a proper determination and consecutive application of the concept of strategic positioning for managing business models, which fundamentally consists of the following constitutive elements ${ }^{4}$ :

* The right goal,

* A value proposition,

* A distinctive value chain,

* Trade-offs,

* Fit among strategy elements,

\& Continuity of direction.

The managerial challenge is to interrelate these elements in order to achieve an organizational dynamism from their predominant static character, in such a manner that it has been achieved in Ikea, Neutrogena etc. In doing so, an organization should initially attempt to achieve its strategic flexibility, a propulsive business concept that is theoretically determined as:

The ability to identify innovation opportunities, commit resources to new courses of action, or reverse unproductive resource deployment (Shimizu and Hitt, 2004; Uhlenbruck, 2003).

Strategic flexibility is influenced by organizational structures and dynamic capabilities, on one hand, and, on the other hand it influences the organizational dynamism, which in return is critical in creating and managing the dynamic business model through reducing the structural complexity and making a full use of a proactive organizational culture. The key determinant in the organizational dynamism are the dynamic capabilities, which refer to:

* A learned and stable pattern of collective activity through which the organization systematically generates and modifies its operating routines in pursuit of improved effectiveness (Zollo and Winter, 2002).

In creating a dynamic business model, dynamic capabilities are interrelated with the forms of knowledge needed for anticipating and proper effecting of customer needs through structures and routines, on the following managerial approach for their dynamic integration ${ }^{5}$ : 
* A relationship between the structures and routines is captured by a firm's business model,

* Existance of a constant and iterative need for creating and sharing the know-how to drive improvements to both structures and routines.

An actual dynamic change mode/ which fulfills the above detailed managerial approaches would best be presented in the following Figure:

Figure 2: A dynamic Business model (Mason and Leek, 2008)

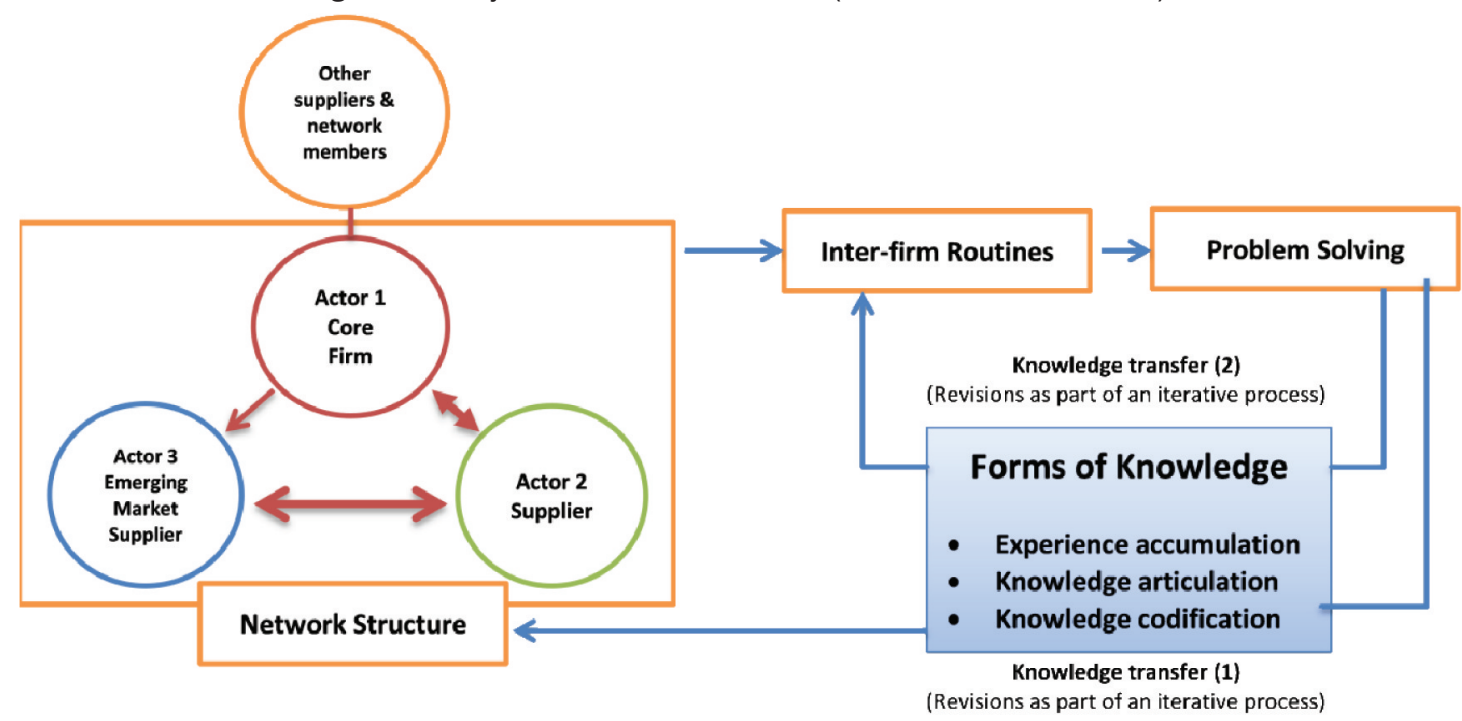

Fundamentally, in order to proactively manage the dynamic character of the business model, it is essential to adopt the need and form of the knowledge of the internal combination of structures and routines, on one hand, and of the nature and depth of the needs of the specific external customer segment, on the other hand.

\section{Conslusion}

Each organized effort for planning and implementing a certain business model integrates not only the organizational, but also the departmental level, especially in those organizational units that are most critical for a proper determination and combination of business elements whose relationship and interdependence form the scope and depth of the competitive potential of any enterprise. In this context, business modelling is $f$ a process rather than a state, predominantly due to the needed changes, transformational or transactional, that shape the process of managing it.

However, it is quite important to emphasize that the concept of business modelling is far from applying the organizational strategy, or operative accommodation of strategic elements. In detailing the desired nature and capacity of their business model, every organization focuses on their particular combination of resources - especially the used knowledge, skills, capabilities and experience, on one hand, and the capacity for a proactive behavior, strategic flexibility and organizational inertia, on the other hand, both of them aimed at reaching the state of organizational dynamism.

Each business model integrates various constitutional elements, predominantly determined as: value proposition, target customer, customer handling/distribution channel, customer interfaces/relationship, value configuration, capability/core competency, partner network, cost structure and revenue model.

The most intriguing issue in creating and managing a most efficient business model is in the proper combination of resources and competencies, aimed at adding value to the organizational performance. A model which pays most attention to it is named the RCOV (Resources and Competencies, Value Proposition, Organization) model in which each combination of the resources and competencies is measured through its marginal influence to the customer quantitative and qualitative benefits. 
The integration of proactivity and organizational inertia leads to a proper determination and consecutive application of the concept of strategic positioning for managing business models. Strategic flexibility is influenced by organizational structures and dynamic capabilities, on one hand, and, on the other hand, it influences the organizational dynamism, which in return is critical for creating and managing of dynamic business model, through reducing the structural complexity and making full use of a pro-active organizational culture.

Fundamentally, in order to proactively manage the dynamic character of the business model, it is essential to adopt the need and form of the knowledge of the internal combination of structures and routines, on one hand, and of the nature and depth of the needs of the specific external customer segment, on the other hand.

\section{REFERENCES}

[1] Bock, J. Adam, Tore Opsahl, Gerald George and David M. Gann (2012, March), The Effects of Culture and Structure on Strategic Flexibility during Business Innovation, Journal of Management Studies, Vol.49, Issue 2, 279-305

[2] Coulson-Thomas, Colin (2013, Autumn), To Business excellence and beyond, Management Services, Vol.57, Issue 3, 18-23

[3] Demil Benoit \& Lecocq Xavier (2010), Business Model Evolution: In Search of Dynamic Consistency, Long Range Planning, Vol. 43, No.2, 227-246

[4] Marx Matt (2008), On a short leash? Young organizations, strategic change and venture capital, Paper presented at the Academy of Management Annual Meeting Proceedings, 1-6

[5] Mason, J. Katy and Leek Sheena (2008, June), Learning to Build a Supply Network: An Exploration of Dynamic Business Models, Journal of Management Studies, Vol.34, Issue 4, 774-799

[6] Mokhlesian Shahin and Holmen Magnus (2012, September), Business model changes and green construction process, Construction Management and Economics, Vol.30, 761-775

[7] Osterwalder, A., Pigneur, Y. \& Tuchi, C.L. (2005), Clarifying Business Models: Origins, Present and Future of the Concept, Communication of the AIS, Vol.16(1), 1-25

[8] Pauwels Koen \& Weiss Allen (2008, May), Moving from free to fee: How nline firms market to change their business model successfully, Journal of Marketing, Vol.72, 14-31

[9] Ple Loic, Lecocq Xavier and Angot Jaques (2010), Customer-Integrated Business Models: A Theoretical Framework, Management, Vol.13, No.4, 226-265

[10] Porter, E. Michael (1997, January-February), What is Strategy, Harvard Business Review, Vol. 75, Issue 1, 156-157

[11] Rasler Kent (2010, December), Run a Proactive, not Reactive Business, Air Conditioning Heating and Refrigerating News, Vol.241, Issue 17, 8-9

[12] Yip S. George (2004, Summer), Using Strategy to change your Business model, Business Strategy Review, Vol.15, Issue 2, 17-24

Receieved: June 2014.

Accepted: September 2014.

${ }^{1}$ Yip S. George (2004, Summer), Using Strategy to change your Business model, Business Strategy Review, Vol.15, Issue 2, p.20

2 Rasler Kent (@010, December), Run a Proactive, not Reactive Business, Air Conditioning Heating and Refrigerating News, Vol.241, Issue 17, p.8

${ }^{3}$ Marx Matt (2008), On a short leash? Young organizations, strategic change and venture capital, Paper presented at the Academy of Management Annual Meeting Proceedings, p.5

${ }^{4}$ Porter E. Michael (1997, January-February), What is Strategy, Harvard Business Review, Vol. 75, Issue 1, p.157

${ }^{5}$ Mason, J. Katy and Leek Sheena (2008, June), Learning to Build a Supply Network: An Exploration of Dynamic Business Models, Journal of Management Studies, Vol.34, Issue 4, p.776 


\section{$1 / 1 / 1 / 1 / 1 / 1 / 1 / 1 / 1 / 1 / 1 / 1 / 1 / 1 / 1 / 1 /$ abouthe author}

Ljubomir Drakulevski
"Ss. Cyril and Methodius" University in Skopje, Faculty of Economics
drakul@eccf.ukim.edu.mk

Ljubomir Drakulevski is full professor at the Faculty of Economics-Skopje, Ss. Cyril and Methodius University in Skopje, engaged as full professor of Strategic Management, International Management and Organizational Behaviour, at the first cycle (undergraduate) and second cycle (postgraduate) of studies at the Faculty of Economics in Skopje. He published 5 books, over 50 papers in the country or abroad, and since from 2011 he has been engaged as Dean of the Faculty of Economics, Ss.

Cyril and Methodius University in Skopje.

\section{Leonid Nakov \\ "Ss. Cyril and Methodius" University in Skopje Faculty of Economics Inakov@eccf.ukim.edu.mk}

Leonid Nakov is associate professor at the Faculty of Economics-Skopje, Ss. Cyril and

Methodius University in Skopje, predominantly focused on the scientific disciplines in the area of Organizational Sciences and Management - Change Management, Business Ethics and Organizational Behaviour, at the first cycle (undergraduate) and the second cycle (postgraduate) of studies at the Faculty of Economics in Skopje. Over the previous period he has published over 30 scientific and research papers in the country and abroad, attended over 40 national and international conferences, symposia, seminars, research studies and summer schools. Leonid Nakov participated in 12 scientific, research or applicative projects, domestic and international, is the only Adizes Top Leaf Moderator in Macedonia and serves as an economic advisor to numerous Macedonian managers. 